\title{
Increased expression of telomere-related proteins correlates with resistance to radiation in human laryngeal cancer cell lines
}

\author{
TIAN TANG ${ }^{1}$, FU-XIANG ZHOU ${ }^{1}$, HAN LEI ${ }^{1}$, HAI-JUN YU ${ }^{1}$, \\ CONG-HUA XIE ${ }^{1}$, YUN-FENG ZHOU ${ }^{1}$ and SHI-QUAN LIU ${ }^{2}$ \\ ${ }^{1}$ Department of Radio-Chemotherapy, Zhongnan Hospital; ${ }^{2}$ State Key Laboratory of \\ Cancer Research, Wuhan University, Wuhan 430071, P.R. China
}

Received October 21, 2008; Accepted December 11, 2008

DOI: 10.3892/or_00000381

\begin{abstract}
Telomere-associated proteins function as survival factors in telomere maintenance, which are major contributors to radiosensitivity in human cancers. The aim of this study was to investigate the association of telomere-associated gene expression and radiation resistance in human larynx squamous carcinoma. The changes of telomere-associated gene expressions and bionomical characteristics that occur in two human larynx squamous carcinoma cell lines (Hep-2 and Hep-2R), with different radiosensitivities in vitro were explored in the present study. Based on previous research, elevated POT1 and TPP1 expressions were detected by reverse transcription-PCR and Western blotting in Hep-2R cell lines. Furthermore, Hep-2R cells showed increased recovery ratio accompanied by a reduction of cell arrested in $\mathrm{G} 2 / \mathrm{S}$ phase, suggesting that the radioresistance of Hep-2R cells was due to a faster growth in which telomere length had recently been demonstrated to be a powerful prognostic marker. These results manifest that radioresistant Hep-2R cell lines showed certain changes in gene expression and bionomical profiles that are different from the profile changes of the moresensitive Hep-2 cell lines, and that evaluation of telomereassociated genes may be a prognostic marker for response to radiotherapy in larynx squamous cell carcinoma (LSCC).
\end{abstract}

\section{Introduction}

Radiation plays an important role in the treatment of cancer. Although modern technology has made it an effective tool,

Correspondence to: Dr Yun-Feng Zhou, Department of RadioChemotherapy, Zhongnan Hospital, Wuhan University, Donghu Road, Wuhan 430071, P.R. China

E-mail: yfzhouwhu@163.com

Abbreviations: LSCC, larynx squamous cell carcinoma; POT1, human protection of telomere1; TPP1, POT1-interacting protein 1; DMEM, Dulbecco's modified Eagle's medium; PLDR, potentially lethal damage repair; EB, ethidium bromide; SF, survival fraction

Key words: larynx squamous carcinoma cell line, radiosensitivity, telomere radiation resistance of tumor cells limit the success of this treatment, and the tumors invariably recur (1-3). In order to improve its therapeutic ratio, there has been much interest in the difference between radioresistant cells and their parental counterparts. As this approach is beginning to show promise, there is a continued need for the discovery of exact mechanisms and the genes involved in enhancing radiotherapeutic response.

Our previous research showed that there must be some intrinsic relationship between telomere length and cellular radiosensitivity. The establishment of a radioresistant human larynx squamous carcinoma cell line (Hep-2R) by repeated irradiation of a radiosensitive line (Hep-2) was also reported (4). This cell line would be a unique and good model to investigate the mechanism or determinant factors for radioresistance. A difference in the gene expression after radiation in these cell lines were detected previously by us (4), which showed that 41 genes and their related molecular pathways related to cell growth and structure were strongly associated with radiation resistance. Nine were reported to be related to cell telomere and DNA reparation, especially the human protection of telomere1 (POT1), which increased more than 3 -fold in Hep-2R cells, but the related genes, especially the expression levels of POT1-interacting protein 1 (TPP1) and relationship with bionomical characteristics in the two cell lines has not yet been validated.

To confirm our outcomes and to clarify the relationship between telomeric proteins and radiosensitivities of human laryngeal cancer cell lines, we investigated the telomeric protein changes correlated with biologic characteristics in human larynx squamous carcinoma cell lines.

\section{Materials and methods}

Cell lines and culture conditions. The human LSCC-derived cell lines Hep-2 and Hep-2R obtained from our previous research were prepared for this study. The cells were maintained in Dulbecco's modified Eagle's medium (DMEM) (Sigma Chemical Co., St Louis, MO, USA) supplemented with $10 \%$ heat-inactivated foetal bovine serum and $50 \mathrm{Uml}^{-1}$ penicillin and streptomycin. All cultures were grown at $37^{\circ} \mathrm{C}$ under a humidified atmosphere of $5 \%$ carbon dioxide for routine growth. 
Irradiation. Cells were plated in $10 \mathrm{~cm}$ dishes and incubated at $37^{\circ} \mathrm{C}$ under humidified $5 \% \mathrm{CO}_{2}, 95 \%$ air in culture medium until $70-80 \%$ confluent. Cells were then exposed to $\gamma$-rays from a ${ }^{60} \mathrm{Co}$-ray source (Atomic Energy of Canada Ltd, Canada and located in Institute, Seoul, Korea) at a dose rate of $61.3 \mathrm{cGy} / \mathrm{min}$.

Evaluation of PLDR. The PLDR in an in vitro system was defined as follows. Appropriate numbers of cells were plated in $25-\mathrm{cm}^{2}$ plastic flasks. After $2 \mathrm{~Gy}$ irradiation of confluent cells, the cells were either immediately plated in $25-\mathrm{cm}^{2}$ plastic flasks or were placed for $8 \mathrm{~h}$ in an incubator (incubation time) to allow cells to repair radiation damage and were then plated (delayed plating). An increase in the surviving fraction (SF) of delayed plating compared with that of immediate plating implies PLDR. Surviving fractions were determined by clonogenic assay as described previously (5). Colonies were fixed and stained with crystal violet (2\% in methanol) at least 14 days after subculture for counting.

Cell cycle analysis. For cell cycle analysis, cells were fixed in $70 \%$ ethanol for at least $1 \mathrm{~h}$ at $4^{\circ} \mathrm{C}$. The fixed cells were then washed once with PBS containing EDTA and resuspended in $1 \mathrm{ml}$ of PBS. After the addition of $10 \mu 1$ each of PI $(5 \mathrm{mg} / \mathrm{ml})$ and RNase $(10 \mathrm{mg} / \mathrm{ml})$, the samples were incubated for $30 \mathrm{~min}$ at $4^{\circ} \mathrm{C}$ and analyzed with a flow cytometer (Beckman Coulter)

$R N A$ isolation and semiquantitative RT-PCR. Total RNA was isolated using TRIzol reagent (Invitrogen) according to the manufacturer's instructions. The first strand of cDNA was obtained using Revert Aid ${ }^{\mathrm{TM}}$ First Strand cDNA Synthesis Kit (Fermentas). For quantitative analysis of POT1 and TPP1 mRNA, human GAPDH gene was used as an internal control. DNA primer sequences were designed as follows: sense CCTTACGTGTTTGGGCATCT and antisense GAA ATGATGCTCCGTCCACT for POT1, sense CCTTGA GGAGCACCTTTCAG and antisense CAGTGTCAGGCAG CTTTCAG for TPP1, and ATCACTGCCACCCAGAA GAC and antisense AGCGTCAAAGGTGGAGGAGT for GAPDH. The cycling conditions for all the cDNA included preincubation for $5 \mathrm{~min}$ at $94^{\circ} \mathrm{C}$ and followed by 30 cycles of $30 \mathrm{sec}$ at $94^{\circ} \mathrm{C}, 40 \mathrm{sec}$ at $54^{\circ} \mathrm{C}, 60 \mathrm{sec}$ at $72^{\circ} \mathrm{C}$ and a final extension for $7 \mathrm{~min}$ at $72^{\circ} \mathrm{C}$. PCR products were identified using electrophoresis on $1.5 \%$ agarose gels containing $0.5 \%$ ethidium bromide (EB). Gel images were obtained and the densities of PCR products were quantified using Bio-ID gel analysis software (Vilber Lourmat, France). All experiments were repeated at least three times.

Polyacrylamide gel electrophoresis and Western blot analysis. Cells were solubilized with lysis buffer $(120 \mathrm{mM}$ $\mathrm{NaCl}, 40 \mathrm{mM}$ Tris, $\mathrm{pH} 8.0$ and $0.1 \%$ NP40), the samples were boiled for $5 \mathrm{~min}$ and equal amounts of protein $(40 \mu \mathrm{g} /$ well) were analyzed on 7.5-10\% SDS-PAGE. After electrophoresis, proteins were transferred to a PVDF membrane and processed for immunoblotting. For the detection of POT1 and TPP1, blots were incubated with 1:100 dilution rabbit polyclonal or monoclonal antibodies (Abnova) and further incubated with horseradish peroxidase-conjugated secondary

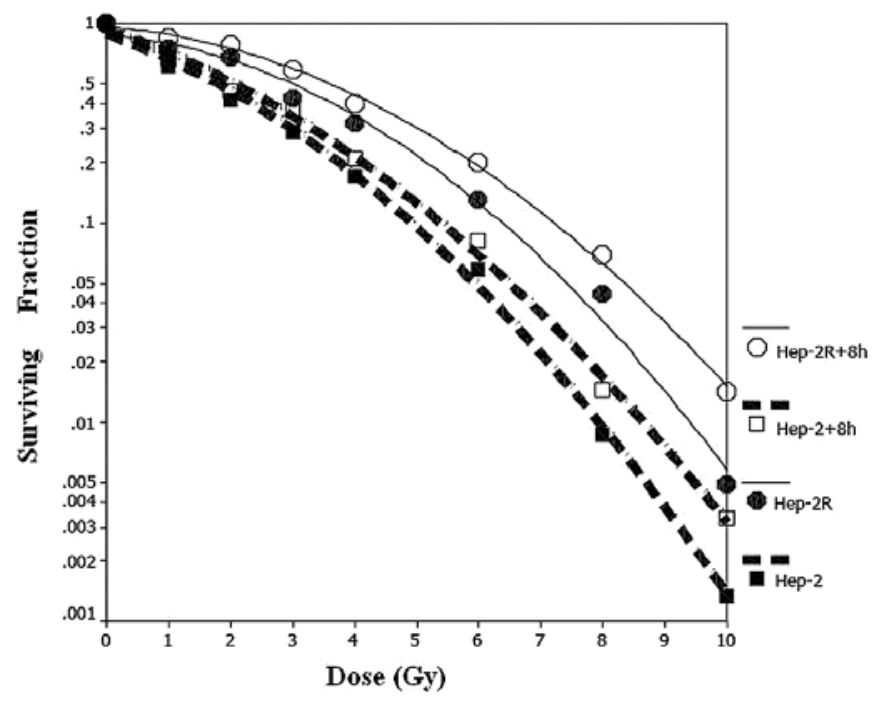

Figure 1. Clonegenic survival assay demonstrating PLDR in both cell lines. Confluent-phase cells were irradiated with 2 Gy and plated immediately after radiation or $8 \mathrm{~h}$ after post-irradiation incubation.

antibody diluted at 1:5000 and specific bands were visualized by ECL (Amersham International). Autoradiographs were recorded onto X-Omat AR film (Eastman Kodak Co.).

Statistical analysis. Data were obtained from triplicate samples and expressed as the mean \pm standard deviation (SD). Statistical analyses were performed by Student's t-test. Statistical analysis was performed using software SPSS 10.0 and Graphic Prism 4.0. $\mathrm{P}<0.05$ was considered to be statistically significant.

\section{Results}

Cell survival curves. As shown in Fig. 1, PLDR was observed in both cell lines. The curve of Hep-2R has a distinct shoulder region, while that of Hep- 2 cells is linear and shows marked radiosensitivity compared to Hep-2R cells. The recovery ratio at 10 Gy was $2.97 \pm 0.5$ in Hep- $2 \mathrm{R}$ and $2.44 \pm 0.6$ in Hep-2, respectively, and was consistent with the difference in radiosensitivity of the two cell lines. The difference was statistically significant $(\mathrm{P}<0.05)$, which indicates that the recovery ratios of radioresistant Hep- $2 \mathrm{R}$ were slightly greater than those of Hep-2. Hep-2R are capable of repairing substantial PLD, whereas little PLD repair occurs in Hep-2 cells.

Hep-2R showed significant changed in cell cycle distribution. The notorious growth retardation of cells induced by radiation prompted us to examine whether cell growth inhibition was affected by changes in cell cycle. Table I exhibited differences in cell cycle phases at $72 \mathrm{~h}$ in Hep-2 and Hep-2R cells. Accumulation of G2-arrested cells was more prominent in Hep-2 than Hep-2R $(22 \pm 1.65 \%$ in Hep-2 and $10.6 \pm 0.97 \%$ in Hep-2R), and the difference in proportion of the cells was statistically significant $(\mathrm{P}<0.05)$.

Altered gene expression, confirmed by RT-PCR and Western blotting, in radiation-resistant clones. We used RT-PCR and 
Table I. Cell cycle distribution of Hep-2 and Hep-2R cells at $72 \mathrm{~h}$ after plated.

\begin{tabular}{lccr}
\hline Group & G1 (\%) & S (\%) & G2 (\%) \\
\hline Hep-2 & $54.2 \pm 1.63$ & $23.8 \pm 1.53$ & $22 \pm 1.65$ \\
Hep-2R & $75.6 \pm 0.72^{*}$ & $13.7 \pm 1.94^{*}$ & $10.6 \pm 0.97^{*}$ \\
\hline
\end{tabular}
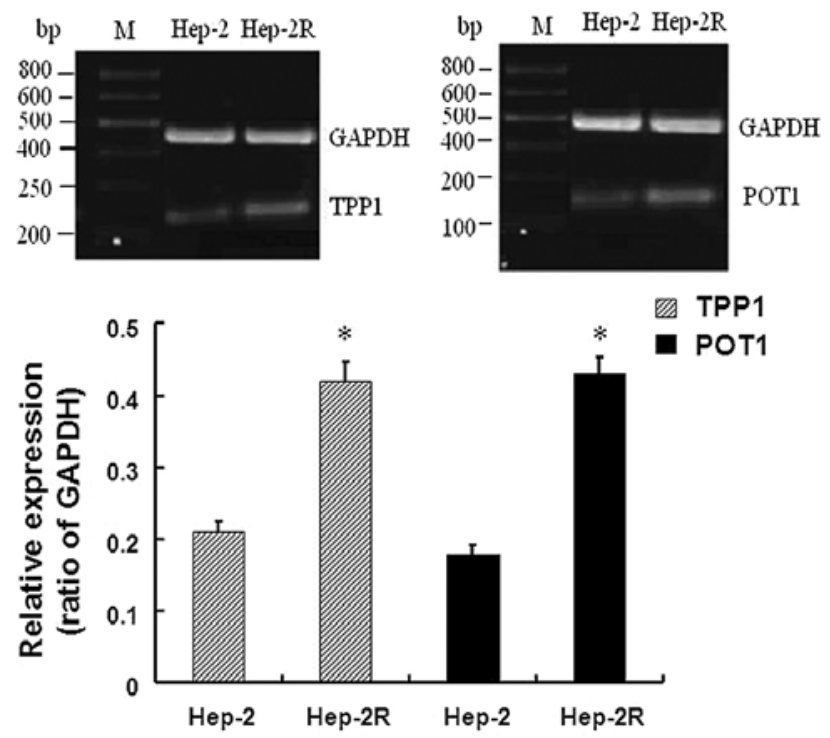

Figure 2. RT-PCR detected TPP1 and POT1 mRNA expression in Hep-2 and Hep-2R cell lines respectively. (A) Representative gels are shown with the upper band displaying GAPDH (452 bp) and the lower band displaying TPP1 (207 bp) or POT1 (135 bp). (B) The PCR products were semiquantified for relative levels of mRNA using image analysis by comparing TPP1 or POT1 with GAPDH. Bar graph shows the mean \pm SD value of relative mRNA expression. ${ }^{*} \mathrm{P}<0.05$ is considered significant.

Western blotting to confirm genes that were differentially expressed in radioresistant Hep-2R clones revealed by microarray, which had indicated that the POT1 showed the most significant alterations in expression in radioresistant clones (3.5-fold increases) (4). So we performed RT-PCR analysis, to further validate the cDNA array approach. As seen in Fig. 2, two genes, including POT1 and TPP1, were selected. Western blot analyses for the two genes were consistent with the results of the cDNA hybridization array and RT-PCR (Fig. 3).

\section{Discussion}

Previous studies have demonstrated that a set of genes related to telomere changed in human laryngeal cancer cell lines with different radiosensitivity (4). In this study, we have further observed that, the expressions of POT1 and TPP1, the important mediator involved in telomere maintenance, were increased in radioresistant Hep-2R than in more sensitive Hep- 2 cell lines at both gene and protein levels. In addition, Hep-2R cells showed higher capacity of potential lethal

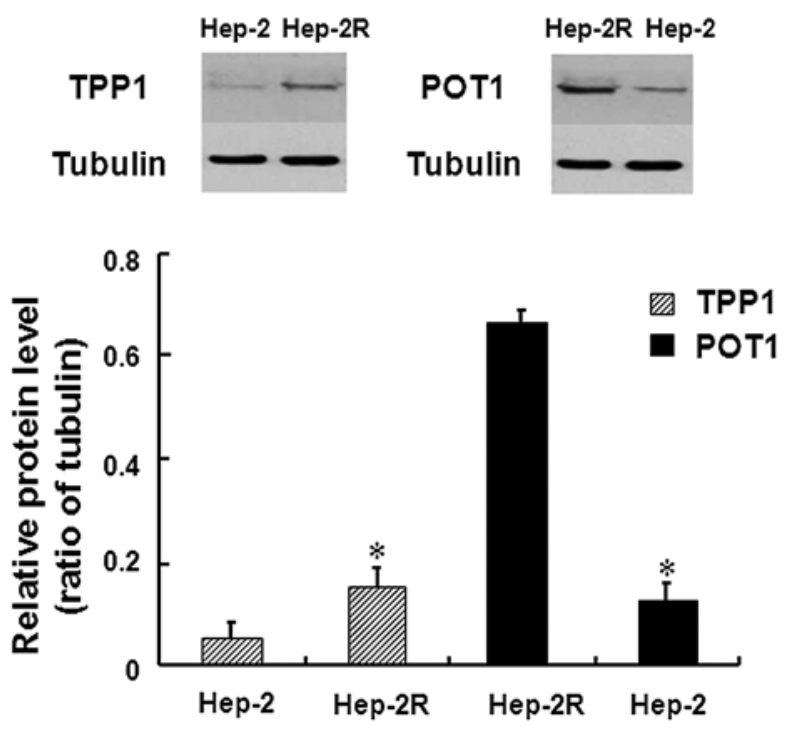

Figure 3. The protein expressions of TPP1and POT1 in Hep-2 and Hep-2R. Protein expressions of TPP1 and POT1 were detected by Western blotting. (A) Representative images are shown of TPP1 and POT1 expression in the Hep-2 and Hep-2R cell lines. (B) The bar chart shows the semiquantitative analysis of TPP1 and POT1 protein expression. Data represent means \pm SD. ${ }^{*} \mathrm{P}<0.05$ is considered significant.

damage repair and an decreased cell numbers in G2/S phase. Therefore, we favor the hypothesis that both POT1 and TPP1 may acts as constitutive and inducible radioresistant factors in human laryngeal cancer.

The cell lines used in this study were derived from the same origin, and they may have similar tumor characteristics. Thus these would be a good model to investigate determinant factors for radiosensitivity. This study demonstrated that PLDR was observed in both Hep-2 and Hep-2R whereas the radioresistant Hep-2R showed higher capacity of PLDR than the radiosensitive Hep-2. Radford et al (6) recently reported that DNA repair capability influences susceptibility to radiation, therefore higher proportion of unrepairable DNA damage in Hep-2 than Hep-2 R may cause different radiosensitivity due to the difference of telomere length.

To determine if the induction of radiosensitivity was associated with accumulation of cells in radiosensitive phases of cell cycle, we investigated cell cycle alterations in the two cell lines. In Hep-2R cells, the percentage of cells in G2/S was significantly reduced with an accumulation of cells in G1 compared with Hep-2 cells. Cells in G2/M are most sensitive and cells in $\mathrm{S}$ phase are mostly radioresistant, which may partially account for the increase in the radioresistance of Hep-2R cells induced by radiation. Furthermore, the magnitude of G2 delay has been shown to detect the degree of radiation-induced DNA damage and cellular radiosensitivity (7), it may be speculated that Hep-2R had less residual DNA damage due to longer telomere length than Hep-2, which was consistent with our previous research suggesting that short telomere length may lead to an impaired DNA repair (8).

Telomeres were originally defined as chromosome caps that prevent the natural ends of linear chromosomes from 
undergoing deleterious degradation and fusion events $(9,10)$. A great number of studies manifest that cellular radiosensitivity is related to the cellular reproductive ability, so there should be some kind of intrinsic correlation between the telomere length and radiosensitivity (11-13). Our previous research also indicated that radiosensitivity is negatively correlated with telomere length, the longer the telomere length, the lower the radiosensitivity (8). Telomere maintenance has been implicated in cancer and ageing, and requires cooperation between a multitude of telomeric factors, including telomerase, TRF1, TRF2, RAP1, TIN2, Tankyrase, PINX1 and POT1 (14-16). Among these proteins, TPP1 and POT1 directly bind single-stranded telomere DNA and interact with a number of proteins to maintain telomere length and structure (17-19). Therefore, the two proteins probably are the major players of telomere maintenance. In a recent study by Wang et al (20), the author showed that TPP1 was the missing $\beta$-subunit of human POT1 protein and proposed that POT1-TPP1 switched from inhibiting telomerase access to the telomere, as a component of shelterin, to serving as a processivity factor for telomerase during telomere extension. O'Connor et al also have reported that the telomeric targeting of POT1 depended on its interaction with TPP1. It remains to be determined how TPP1 interacts with other telomeric proteins and whether TPP1 has any function other than targeting POT1 (21).

In the present study, we detected expression of POT1 and TPP1 both at gene and protein levels, which showed that both them were elevated in Hep-2R cells. Although these changes have to be confirmed by further experiments, they are expected to greatly affect the function of telomeres in radioresistant clones. A yin-yang model (22) in which TPP1 and POT1 function as a unit to protect human telomeres, indicated they both positively and negatively regulated telomerase access to telomere DNA. The lower expression level of various factors involved in telomerase activity should impair telomere regeneration at each $\mathrm{S}$ phase (23). Moreover, the altered expression of telomere capping factors might disrupt the capping complex, facilitating telomere degradation and shortening independently of the telomerase status $(24,25)$. This correlates with telomeric damage possibly already appeared in LSCC cells, which may be one of the reasons as to why shortened telomeres result in increased sensitivity to ionizing radiation exposure.

In conclusion, our results provide the first evidence of the expression of telomere-associated genes in LSCC, which suggests that high level of TPP1 and POT1 seems to be directly associated with poor radiosensitivity in LSCC cells as independent predicting factors. Although an accurate delivery system of siRNA to target cells is yet to be established, we believe that this mechanism is worthy of further research.

\section{Acknowledgements}

We thank Dr Zhiguo Luo and Shiquan Liu for excellent technical assistance. This study was supported by the Natural Science Foundation of China (30171063).

\section{References}

1. Saydam O, Saydam N, Glauser DL, Pruschy M, Dinh-Van V, Hilbe M, Jacobs AH, Ackermann M and Fraefel C: HSV-1 amplicon-mediated post-transcriptional inhibition of Rad51 sensitizes human glioma cells to ionizing radiation. Gene Ther 14: 1143-1151, 2007.

2. Gosepath EM, Eckstein N, Hamacher A, Servan K, von Jonquieres G, Lage H, Györffy B, Royer HD and Kassack MU: Acquired cisplatin resistance in the head-neck cancer cell line Cal27 is associated with decreased DKK1 expression and can partially be reversed by overexpression of DKK1. Int J Cancer 123: 2013-2019, 2008.

3. Hara T, Omura-Minamisawa M, Kang $\mathrm{Y}$, Cheng $\mathrm{C}$ and Inoue $\mathrm{T}$ : Flavopiridol potentiates the cytotoxic effects of radiation in radioresistant tumor cells in which p53 is mutated or Bcl-2 is overexpressed. Int J Radiat Oncol Biol Phys 71: 1485-1495, 2008.

4. Zhou FX, Xiong J, Luo ZG, Liao ZK, Liu SQ and Zhou YF: Human radiosensitive-radioresistant cell lines model and its cDNA expression profiles. Radiat Res (In press).

5. Zhou FX, Liao ZK, Dai J, Xiong J, Xie CH, Luo ZG, Liu SQ and Zhou YF: Radiosensitization effect of zidovudine on human malignant glioma cells. Biochem Biophys Res Commun 59: 351-356, 2007.

6. Radford IR and Aldridge DR: Importance of DNA damage in the induction of apoptosis by ionizing radiation: effect of the scid mutation and DNA ploidy on the radiosensitivity of murine lymphoid cell lines. Int J Radiat Biol 75: 143-153, 1999.

7. Iliakis G, Wang Y, Guan J and Wang H: DNA damage checkpoint control in cells exposed to ionizing radiation. Oncogene 22: 5834-5847, 2003

8. Zhong YH, Liao ZK, Zhou FX, Xie CH, Xiao CY, Pan DF, Luo ZG, Liu SQ and Zhou YF: Telomere length inversely correlates with radiosensitivity in human carcinoma cells with the same tissue background. Biochem Biophys Res Commun 367: 84-89, 2008.

9. Deng Y, Chan SS and Chang S: Telomere dysfunction and tumour suppression: the senescence connection. Nat Rev Cancer 8: 450-458, 2008.

10. Rong YS: Telomere capping in Drosophila: dealing with chromosome ends that most resemble DNA breaks. Chromosoma 117: 235-242, 2008.

11. Zongaro S, Verri A, Giulotto E and Mondello C: Telomere length and radiosensitivity in human fibroblast clones immortalized by ectopic telomerase expression. Oncol Rep 19: 1605-1609, 2008

12. de Souza Nascimento P, Alves G and Fiedler W: Telomerase inhibition by an siRNA directed against hTERT leads to telomere attrition in HT29 cells. Oncol Rep 16: 423-428, 2006.

13. Barwell J, Pangon L, Georgiou A, Docherty Z, Kesterton I, Ball J, Camplejohn R, Berg J, Aviv A, Gardner J, Kato BS, Carter N, Paximadas D, Spector TD and Hodgson S: Is telomere length in peripheral blood lymphocytes correlated with cancer susceptibility or radiosensitivity? Br J Cancer 97: 1696-1700, 2007.

14. Hockemeyer D, Palm W, Else T, Daniels JP, Takai KK, Ye JZ, Keegan CE, de Lange T and Hammer GD: Telomere protection by mammalian Pot1 requires interaction with Tpp1. Nature Struct Mol Biol 14: 754-761, 2007.

15. Xin H, Liu D and Songyang Z: The telosome/shelterin complex and its functions. Genome Biol 9: 232, 2008.

16. Wu Y, Mitchell TR and Zhu XD: Human XPF controls TRF2 and telomere length maintenance through distinctive mechanisms. Mech Ageing Dev 129: 602-610, 2008.

17. Liu D, O'Connor MS, Qin J and Songyang Z: Telosome, a mammalian telomere-associated complex formed by multiple telomeric proteins. J Biol Chem 279: 51338-51342, 2004.

18. Miyoshi T, Kanoh J, Saito M and Ishikawa F: Fission yeast Pot1-Tpp1 protects telomeres and regulates telomere length. Science 320: 1341-1344, 2008.

19. Barrientos KS, Kendellen MF, Freibaum BD, Armbruster BN, Etheridge KT and Counter CM: Distinct functions of POT1 at telomeres. Mol Cell Biol 28: 5251-5264, 2008.

20. Wang F, Podell ER, Zaug AJ, Yang Y, Baciu P, Cech TR and Lei M: The POT1-TPP1 telomere complex is a telomerase processivity factor. Nature 445: 506-510, 2007. 
21. O'Connor MS, Safari A, Xin H, Liu D and Songyang Z: A critical role for TPP1 and TIN2 interaction in high-order telomeric complex assembly. Proc Natl Acad Sci USA 103: 11874-11879, 2006

22. Xin H, Liu D, Wan M, Safari A, Kim H, Sun W, O'Connor MS and Songyang Z: TPP1 is a homologue of ciliate TEBP-beta and interacts with POT1 to recruit telomerase. Nature 445: 559-562, 2007.

23. Meeker AK: Telomeres and telomerase in prostatic intraepithelial neoplasia and prostate cancer biology. Urol Oncol 24: $122-130,2006$
24. Smith CD and Blackburn EH: Uncapping and deregulation of telomeres lead to detrimental cellular consequences in yeast. J Cell Biol 145: 203-211, 1999

25. Maes L, Van Neste L, Van Damme K, Kalala JP, De Ridder L, Bekaert S and Cornelissen M: Relation between telomerase activity, hTERT and telomere length for intracranial tumours. Oncol Rep 18: 1571-1576, 2007. 